\title{
The Manufacture and Nutritional Chemical Analysis of Daucus carota L. var. sativa Hoffm. Jam \\ Guo $\mathrm{Hu}^{1}$ and Shangqin $\mathrm{Hu}^{2}$ \\ ${ }^{1}$ College of Fine Arts Chongqing Normal University, Chongqing, China \\ ${ }^{2}$ College of Life Science Chongqing Normal University, Chongqing, China \\ hushangqin@163.com
}

Keywords: Daucus carota L. var. sativa Hoffm. Jam; Chemical composition; Manufacture; Analysis

\begin{abstract}
To develop the Daucus carota L. var. sativa Hoffm. industry in our country, the further development and utilization of Daucus carota L. var. sativa Hoffm. agricultural resources, using modern processing technology to Daucus carota L. var. sativa Hoffm. processed into Daucus carota L. var. sativa Hoffm. Jam. So as to provide scientific basis for the relevant departments and enterprises and related production units.

Using mechanical processing technology, the Daucus carota L. var. sativa Hoffm processed into carrot paste, and by chemical analysis methods and modern instrument, chemical composition of Daucus carota L. var. sativa Hoffm Jam to carry out a full range analysis

The findings indicated that, the Daucus carota L. var. sativa Hoffm. jam manufacture craft is simple, the cost is low, does not need the expensive specific installation, is advantageous in the Daucus carota L. var. sativa Hoffm. jam production processing technology promotion and the Daucus carota L. var. sativa Hoffm. jam development intensive processing. In the sauce the nutrition is rich, the amino acid is complete, including 17 kind of above amino acids and the human body 8 kind of essential amino acids, the protein content $1.85 \%$, fat content $1.56 \%$, cellulose content $0.87 \%$, carbohydrate content $8.21 \%$. Vitamin C quite is specially high for $19.9 \mathrm{mg} / 100 \mathrm{~g}$, the potassium, the calcium, the iron, the zinc content are rich, respectively is $30.0 \mathrm{mg} / 100 \mathrm{~g}$, $34 . .1 \mathrm{mg} / 100 \mathrm{~g} 1.42 \mathrm{mg} / 100 \mathrm{~g}, 0.24 \mathrm{mg} / 100 \mathrm{~g}$ Moreover the flavor is tasty, it is easy to digest, enhances the nutrition the use factor, and also eliminated Daucus carota L. var. sativa Hoffm. jam the general edible method to cause the inflation shortcoming.

The Daucus carota L. var. sativa Hoffm. jam is one of the nutrition for the old and seasiongs young. This has provided the scientific basis for the Daucus carota L. var. sativa Hoffm. Thorough research and the development . It is one kind concurrently suitable nutrition rich newest seasoning for the old and young
\end{abstract}

\section{Introduction}

Daucus Carota L. var. sativa Hoffm. is a Biennial herbs plants of the Umbelliferae carrot genus[1,2].Chinese medicine believes that carrot warm sweet, flat. Has Jianpixiaoshi, Liver eyesight, detoxification, rash, cough antiasthmatic. Carrot and enhance resistance and indirectly destroy the cancer cells, blood sugar, reduce blood fat, blood pressure, promote the synthesis of adrenaline, strong heart function in patients with hypertension and coronary heart disease, is a good food. And carrot every 100 grams of fresh weight with $1.67 \sim 12.1 \mathrm{mg}$ carotene content higher than $5 \sim 7$ times of tomato, edible after digestion into vitamin A, can prevent night blindness and respiratory diseases.

The present situation of production and trade in China in China Gan Xun, carrot carrot planting area close to the world of the total planted area of $40 \%$, the total output accounted for $1 / 3$ of the total output of the world, is the world's largest fully deserve carrot production in china. China in Shandong, Hebei, Liaoning, Jilin, Inner Mongolia area, water sufficient area, yield is higher, can reach 4500-6500 kg. Jingbian County Dongkeng Town of Yi Wan Village in 2015 a pound of carrot to sell 1.5 yuan, an average yield per mu in 10 thousand jins, light Daucus Carota L. var. sativa Hoffm an income reached 300 thousand yuan. 2016 the village planted more than 20 acres of carrot 
farmers income of more than 500 thousand yuan a large number of export exported to South Korea, Dubai, Japan, singapore.

At present the Daucus Carota L. var. sativa Hoffm planting area and yield are the forefront of the world, but the mechanization level is very low, most of the artificial planting, or simple planter is inefficient, and the harvest is mainly rely on manual, how to improve the further study of $[3,4,5,6,7,8]$ Daucus Carota L. var. sativa Hoffm planting and harvesting mechanization and modernization and deep the processing technology and so on.

This paper aims to develop carrot industry in our country, the further development and utilization of carrot agricultural resources, using the mechanical processing method of the carrot processed into carrot paste, and by chemical analysis methods and modern instrument, chemical composition of Daucus Carota L. var. sativa Hoffm Jam to carry out a full range analysis. So as to provide scientific basis for the relevant departments and enterprises and related production units.

\section{Materials and Methods}

Materials. Daucus Carota L. var. carrot sativa Hoffm. from Chongqing city of Shapingba Chen Jia Wan vegetable market to buy.

Reagent: glutamic acid, alanine, glycine, leucine, isoleucine, arginine, lysine and threonine

Acid, valine, phenylalanine, tyrosine, histidine, serine, aspartic acid, methionine, vitamins.

B1, B2, B5, B6, B11, B12, vitamin C, beef extract, peptone, sodium chloride, sulfuric acid, hydrochloric acid, potassium sulfate.

Salt, edible oil, etc..

Instruments and equipment: fat extraction equipment, 2300 grams of protein analyzer (KJELTEC2300, Sweden),

Ultraviolet spectrophotometer (uv-9100), tissue grinder (JJ-2), amino acid analyzer (Aas vario 6), atomic absorption spectrophotometer, clean bench, asepsis room, pressure cooker, oven, Soxtec Avanti2055 fat tester (Forster card holding company).

Method. Process flow

Daucus Carota L. var. carrot sativa Hoffm. $\rightarrow$ raw material removal with mud $\rightarrow$ pest root part (soil and weeds) $\rightarrow$ wash $\rightarrow$ scrape the hair with sediment epidermis $\rightarrow$ cut into small pieces $\rightarrow$ boiling $\rightarrow$ add $40 \%$ root cast mill $\sim 50 \%$ water pulping $\rightarrow$ add salt and other accessories $\rightarrow$ bottlin $\rightarrow$ gpasteurization $\rightarrow$ sampling $\rightarrow$ storing

Daucus Carota L. var. carrot sativa Hoffm. Jam processing technology

Daucus Carota L. var. carrot sativa Hoffm Because the carrot growth process is the growth of roots in the mud and often a lot of dirt, dirt must be removed before processing, scraping with hair skin after fully rinse after cooking and then beating, beating, adding proper amount of water (40\% $50 \%$ ) for pulping, pulp to fine. Environmental sanitation requirements of processing (in the asepsis room), beater and utensils should be sterilized containers. The plasma made with salt 7 10\%, 0.4\% pepper, pepper $5 \%$, umami $1 \%$, ginger $6 \%$, vegetable oil $1 \% \sim 3 \%$, mixing, bottling, pasteurization disinfection, sampling qualified after storage, low temperature or normal temperature preservation.

Methods for the determination of nutritional components of Daucus Carota L. var. carrot sativa Hoffm Jam.

Determination of protein content by Gil Turk 2300 Protein analyzer. Determination of fat content by Avanti2055 Soxtec fat detector method [6]. Determination of vitamin [6] by liquid chromatography volumetric method. Determination of amino acid content by Hitachi L-8800 amino acid analyzer [6]. Determination of mineral content [6] by Hitachi Z-5000 atomic absorption spectrophotometer. The determination of carbohydrate by [6] volumetric method. Determination of color aroma by sensory method [7].

The Results of Analysis. Analysis of nutritional components of Daucus Carota L var. carrot sativa Hoffm Jam.

Daucus Carota L var. carrot sativa Hoffm Jam., according to Li Heng, Wang Jirang, sensory identification of food sensory evaluation method Mingxun, its nutrient rich flavor (good taste) delicious aroma, with the whole body, the color is red brown. After the determination of the protein, 
fat, carbohydrate, high cellulose content, the results in Table 1 and Fig. 1.

Table 1. Daucu Csarota L var. carrot sativa Hoffm Jam main nutrient content (mg /100g)

$\begin{array}{ccc}\text { Component name } & \begin{array}{c}\text { contents in Daucus Carota } \\ \text { var. carrot sativa Hoffm Jam }\end{array} & \text { Content in raw materials } \\ & 1.85 & 0.99 \\ \text { protein } & 156 . & 0.25 \\ \text { crude fat } & 821 & 780 \\ \text { carbohydrate } & 0.87 & 0.80 \\ \text { Crude cellulose } & \end{array}$

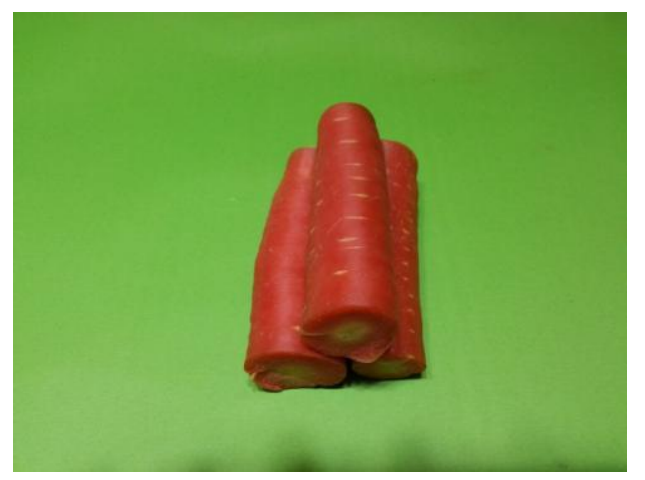

Figure 1. Daucu Csarota L var. carrot sativa Hoffm raw material

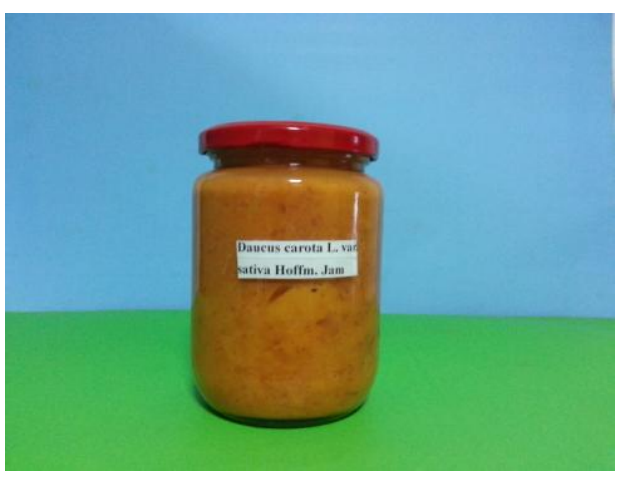

Daucu Csarota L var. carrot sativa Hoff Jam products

The results can be seen from table 1, $1.85 \mathrm{mg} / 100 \mathrm{~g}$, . Daucu Csarota L var. carrot sativa Hoffm Jam protein content $1.56 \mathrm{mg} / 100 \mathrm{~g}$ fat, carbon waterCompound $821 \mathrm{mg} / 100 \mathrm{~g}$, cellulose $0.87 \mathrm{mg} / 100 \mathrm{~g}$. The four major nutrient content of carrot Jiangzhong are very rich in protein is the main nutrient elements necessary for the human body, and it is closely related to life activities, no protein, no life is unimaginable, life is a protein found in the way.

Analysis of amino acids and the content of. Daucu Csarota L var. carrot sativa Hoffm Jam Determination of kinds and contents of amino acids in. Daucu Csarota L var. carrot sativa Hoffm Jam using Hitachi L-8800 automatic amino acid analyzer, the results are shown in Table 2

Table 2 Daucu Csarota L var. carrot sativa Hoffm Jam amino acid content(mg/100g)

\begin{tabular}{lccccc}
\hline Serial number & Name & content & Serial number & Name & content \\
\hline 1 & Asn & 310 & 10 & Ile & 2.18 \\
2 & Thr & 2.34 & 11 & Leu & 2.61 \\
3 & Ser & 2.48 & 12 & Tyr & 1.62 \\
4 & Glu & 7.75 & 13 & Phe & 1.79 \\
5 & Gly & 2.21 & 14 & Lys & 3.55 \\
6 & Ala & 2.34 & 15 & His & 1.40 \\
7 & Cys-Cys & 0.12 & 16 & Arg & 3.43 \\
8 & Val & 2.38 & 17 & Pro & 0.80 \\
9 & Met & 1.10 & & & \\
\hline
\end{tabular}

Seen from table 2, Daucu Csarota L var. carrot sativa Hoffm Jam amino acid, contains 17 kinds of amino acids, 8 kinds of essential amino acids, which is a new type of amino acid.

Analysis of Daucu Csarota L var. carrot sativa Hoffm Jam vitamin content 
Determination of vitamin content of Daucu Csarota L var. carrot sativa Hoffm Jam by liquid chromatography volumetric method, the results in table 3.

Table 3 Daucu Csarota L var. carrot sativa Hoffm Jam vitamin content ( $\mathrm{mg} / 100 \mathrm{~g}$ )

\begin{tabular}{cccc}
\hline Content name & content & Content name & content \\
\hline $\mathrm{VA}$ & 1.90 & $\mathrm{VC}$ & 19.9 \\
$\mathrm{VPP}$ & 0.12 & $\mathrm{VB}_{2}$ & 0.14 \\
$\mathrm{VB}_{3}$ & 011 & $\mathrm{VB}_{1}$ & 0.29 \\
\hline
\end{tabular}

We can be seen from table 3, the content of vitamin Jiangzhong carrot is rich in vitamin C content, which is the highest of $19.9 \mathrm{mg} / 100 \mathrm{~g}-\mathrm{g}-1$, followed by vitamin A1.90mg/100g, vitamin B1 and B2 $0.14 \mathrm{mg} / 100 \mathrm{~g}$. Vitamin is one of the 6 major nutritional elements of the human body, is an important nutrient for human health. If the human body for a long time the lack of a vitamin can cause the typical deficiency of the vitamin. For this reason, people have to eat enough vitamin to ensure the normal physiological function of the body. Carrot is Jiangzheng meet this requirement.

Analysis of Ducu Csarota L var. carrot sativa Hoffm Jam mineral elements

Ducu Csarota L var. carrot sativa Hoffm Jam by Hitachi Z-5000 atomic absorption spectrophotometer method, the mineral content is shown in Table 4

Table 4 Ducu Csarota L var. carrot sativa Hoffm Jam mineral elements (mg/100g)

\begin{tabular}{lcc}
\hline Element name & abbreviation & content \\
\hline potassium & $\mathrm{K}$ & 192.1 \\
chlorine & $\mathrm{CL}$ & 2.11 \\
calcium & $\mathrm{C}_{\mathrm{a}}$ & 34.1 \\
magnesium & $\mathrm{M}_{\mathrm{g}}$ & 15.0 \\
iron & $\mathrm{F}_{\mathrm{e}}$ & 1.42 \\
copper & $\mathrm{Cu}$ & 0.05 \\
zinc & $\mathrm{Z}_{\mathrm{n}}$ & 0.24 \\
sodium & $\mathrm{Na}$ & 75.6 \\
phosphorus & $\mathrm{P}$ & 30.0 \\
\hline
\end{tabular}

Table 4 shows that the results of Ducu Csarota L var. carrot sativa Hoffm Jam in mineral range. Potassium, calcium, magnesium, iron, zinc, rich in content. They are all essential elements of the human body. The calcium content as high as $34.1 \mathrm{mg} / 100 \mathrm{~g}$, it is the most important in the human body and organism, calcium is the main mineral elements that constitute the human body, the body will appear calcium deficiency rickets and osteoporosis. Potassium content is high $192.1 / 100 \mathrm{~g} \mathrm{mg}$, potassium can promote the activity of the human body, the heart is weak and hypertension disease have certain curative effect. Zinc is $0.24 / 100 \mathrm{~g} \mathrm{mg}$, zinc is one of the very important elements. The iron content of $1.42 \mathrm{mg} / 100 \mathrm{~g}$, which is of some enzymes (e.g. decarboxylase) cofactor, human iron deficiency can cause anemia disease. Therefore, calcium, iron, zinc, potassium and other minerals play an important role in the human body is an important part of the study of mineral elements in food, but also one of the important signs of food nutrition. So the Ducu Csarota L var. carrot sativa Hoffm Jam is a unique seasoning in this respect.

\section{Conclusions}

The results show that Ducu Csarota L var. carrot sativa Hoffm paste production process is simple, low cost, no special equipment expensive, is conducive to the development of deep processing production technology and the promotion of Daucu Csarta L var. carrot sativa Hoffm . Daucu Csarota L var. carrot sativa Hoffm Jam is rich in nutrition, amino acids, containing more than 17 
kinds of amino acids and 8 kinds of essential amino acids, protein content, fat content, $1.85 \mathrm{mg} / 100 \mathrm{~g}$, $1.56 \mathrm{mg} / 100 \mathrm{~g}, 0.87 \mathrm{mg} / 100 \mathrm{~g}, 821 \mathrm{mg} / 100 \mathrm{~g}$, cellulose content, carbohydrate content. In particular, vitamin $\mathrm{C}$ is relatively high for $19.9 \mathrm{mg} / 100 \mathrm{~g}$, potassium, calcium, iron, zinc, rich in content, respectively, $/ 100 \mathrm{~g} 1.42 \mathrm{mg} / 100 \mathrm{~g}, \mathrm{Mg}, 0.24 / 100 \mathrm{~g} 192.1 \mathrm{mg}$. But delicious, this is made after such processed carrot paste products, not only changed the past single eat, improve the utilization rate of nutrient, and increase the need for new varieties of Ducu Csarota L var. carrot sativa Hoffm market. The latest is a condiment for both young and old rich nutrition.

\section{References}

[1] Jiang Bingwu: carrot pollution-free cultivation method [J], friends of farmers to become rich, 2013, (07): 26-27

[2] Wu Mingkun: pollution-free cultivation techniques of carrot [J], 2012 China extension, (7): 27-28

[3] Guo Zhaojuan, Wu Huanzhang et al: 7 Ducu Csarota L var. carrot sativa Hoffm intercropping planting pattern, modern agricultural science and technology [J], 2013 (5), 131-134

[4] Gao Caiyun, Liang Zhenying: no analysis, current situation and Prospect of industrial pollution and Ducu Csarota L var. carrot sativa Hoffm cale planting fort village in Duolun County Development of agriculture, Characteristic agriculture[J] 2015 (2), 14-15

[5] Gao ya, Han Yanqiu, etc., Ducu Csarota L var. carrot sativa Hoffm storage technology in Liaoning area, agricultural science and technology and equipment $[\mathrm{J}], 5(7)$

[6] Xue Na,Wang Guangfei, Northern Shaanxi sandy loam soil Ducu Csarota L var. carrot sativa Hoffm planting technology, vegetable cultivation[J], 2016 (7), 32

[7] Li Yaping, Wu Pingfeng, Huw Rob Mi Dan Shui George: the nutrition research of infantile diarrhea, International Journal of laboratory medicine [J] 2015 (36), supplement, 67-68

[8] Yang Wei, Li Jiandong, et al. The present situation and thinking of carrot planting and harvesting mechanization [J], mechanization research, 2014, (12): 247-248

[9] Huang Weikun. Food analysis and inspection [M], Beijing, light industry press, 1989, 17-705

[10] Li Heng, Wang Jirang, Qu Ming Xun. The identification method of food sensory and practice [M], Shanghai science and Technology Literature Press, 1990, 10.116-141 